\section{Evaluation of Wi-Fi Radiation Effects on Antibiotic Susceptibility, Metabolic Activity and Biofilm Formation by Escherichia Coli 0157H7, Staphylococcus Aureus and Staphylococcus Epidermis}

\author{
Said-Salman I. H. ${ }^{1,2 \odot}$, Jebaii F. A. ${ }^{* *}{ }^{\bullet}$, Yusef H. H. ${ }^{4}$, Moustafa \\ M. E. ${ }^{5}$
}

\begin{abstract}
Background: The radiation emitted from electromagnetic fields (EMF) can cause biological effects on prokaryotic and eukaryotic cells, including non-thermal effects.

Objective: The present study evaluated the non-thermal effects of wireless fidelity (Wi-Fi) operating at $2.4 \mathrm{GHz}$ part of non-ionizing EMF on different pathogenic bacterial strains (Escherichia coli 0157H7, Staphylococcus aureus, and Staphylococcus epidermis). Antibiotic resistance, motility, metabolic activity and biofilm formation were examined.
\end{abstract}

Material and Methods: In this case-control study, a Wi-Fi router was used as a source of microwaves and also bacterial cells were exposed to Wi-Fi radiation continuously for 24 and 48 hours. The antibiotic susceptibility was carried out using a disc diffusion method on Müller Hinton agar plates. Motility of Escherichia coli $0157 \mathrm{H} 7$ was conducted on motility agar plates. Cell metabolic activity and biofilm formation were performed using 3-(4, 5-Dimethylthiazol-2yl)-2, 5-diphenyltetrazolium bromide (MTT) assay and crystal violet quantification, respectively.

Results: The exposure to Wi-Fi radiation altered motility and antibiotic susceptibility of Escherichia coli $0157 \mathrm{H} 7$. However, there was no effect Wi-Fi radiation on antibiotic susceptibility of Staphylococcus aureus and Staphylococcus epidermis. On the other hand, the exposed cells, as compared to the unexposed control, showed an increased metabolic activity and biofilm formation ability in Escherichia coli 0157H7, Staphylococcus aureus and Staphylococcus epidermis.

Conclusion: These results proposed that Wi-Fi exposure acted on bacteria in stressful manner by increasing antibiotic resistance and motility of Escherichia coli 0157H7, as well as enhancing biofilm formation by Escherichia coli 0157H7, Staphylococcus aureus and Staphylococcus epidermis. The findings may have implications for the management of serious diseases caused by these infectious bacteria.

Citation: Said-Salman I. H, Jebaii F. A, Yusef H. H, Moustafa M. E. Evaluation of Wi-Fi Radiation Effects on Antibiotic Susceptibility, Metabolic Activity and Biofilm Formation by Escherichia Coli 0157H7, Staphylococcus Aureus and Staphylococcus Epidermis. J Biomed Phys Eng. 2019;9(5):579-586. https://doi.org/10.31661/jbpe.v0i0.1106.

\section{Keywords}

Non-thermal Effect; EMF; Wi-Fi; Disc Diffusion; Motility; MTT; Biofilms; Escherichia coli; Staphylococcus

\section{Introduction}

ver the past century, the natural environment has been altered by greater the use of telecommunication, such as global system for mobile communication (GSM) and wireless fidelity (Wi-Fi). Wi-
${ }^{1} \mathrm{MSc}$, Department of Biological Sciences, Faculty of Science, Beirut Arab University, Lebanon ${ }^{2} \mathrm{MSc}$, Department of Biochemistry, Faculty of Science, Lebanese University, Lebanon ${ }^{3} \mathrm{PhD}$, Department of Biochemistry, Faculty of Science, Lebanese University, Lebanon ${ }^{4} \mathrm{PhD}$, Department of Biological Sciences, Faculty of Science, Beirut Arab University, Lebanon ${ }^{5} \mathrm{PhD}$, Department of Biochemistry, Faculty of Science, Alexandria University, Egypt

*Corresponding author: F. A. Jebaii

Department of Biochemistry, Faculty of Science,

Lebanese University, Lebanon

E-mail: f.jebai@gmail. com

Received: 8 January 2019 Accepted: 6 February 2019 
Fi waves are a part of the non-ionizing radiation of the electromagnetic spectrum and they use radiofrequency typically operating at 2.4 $\mathrm{GHz}$ [1]. Non-ionizing electromagnetic radiation affects biological system through either thermal or non- thermal effects [1,2]. Many scientific studies have investigated biological effects of electromagnetic fields (EMF) [1-3]. Non-thermal EMF induced different responses on bacteria depending on frequency intensity, exposure time and organism model [4].

Several studies investigated the non-thermal effects of high frequency electromagnetic fields (GSM and Wi-Fi) on different strains of bacteria [5-11]. Exposure of Staphylococcus aureus, Staphylococcus epidermis, and Pseudomonas aeruginosa to GSM revealed no effects on their bacterial growth rate or antibiotic susceptibility [7]. However, others reported that exposure to Wi-Fi and GSM altered the inhibition zone diameters and growth rate for of Escherichia coli and Listeria monocytogenes [8]. In addition, Wi-Fi radiation significantly increased the sensitivity of klebsiella pneumoniae to different antibiotics followed by a decrease suggesting an adaptive response [9].

The aim of this study was to analyze the influences of electromagnetic fields $(2.4 \mathrm{GHz})$ emitted by a WI-FI router on the antibiotic resistance, cell metabolic activity and ability to form biofilm by different pathogenic strains (Escherichia coli 0157H7, Staphylococcus aureus, and Staphylococcus epidermis).

\section{Material and Methods}

\section{Microwave exposure system}

The microwave (MW) source was generated continuously by $54 \mathrm{M}$ wireless router Tp-Link extended range (TL-WR524G) corresponding to the appropriate frequency $2.4 \mathrm{GHz}$ connected to an amplifier and monopole antenna, then mounted in an incubator which was kept at $37^{\circ} \mathrm{C}$ at $30 \mathrm{~cm}$ of distance from bacterial culture. The exposure protocol consisted of a phase of continuous exposure to the MW for
24 or 48 hours. For each experimental condition, a control was performed in Faraday bag at the same temperature to limit any exterior radiation.

\section{Bacterial strains}

The bacterial strains used in the current in vitro case-control study were Escherichia coli 0157H7, Staphylococcus aureus and Staphylococcus epidermis. They were provided by the Microbiology Laboratory, Faculty of Science, Beirut Arab University (BAU), Lebanon. The isolates were checked for their purity and identity. The growth of colorless transparent colonies on sorbitol MacConkey agar medium (Oxoid) confirmed the inability of E. coli $0157 \mathrm{H} 7$ to ferment sorbitol [12]. API Staph was used to confirm the identification of $S$. aureus and S. epidermis.

\section{Antimicrobial Susceptibility}

Müller Hinton agar medium (Oxoid) was used for susceptibility testing based on the criteria of the National Committee for Clinical Laboratory Standards [13]. The isolated $E$. coli $0157 \mathrm{H} 7$ was tested for sensitivity to the antimicrobials (Oxoid), including Meropenem (MEM) $10 \mu \mathrm{g}$, Imipenem (IMI) $10 \mu \mathrm{g}$, Rifampicin (RD) $30 \mu \mathrm{g}$, Levofloxacin (Lev) $5 \mu \mathrm{g}$, Oflaxacin (OFX) $5 \mu \mathrm{g}$, and Chloramphenicol (C) $10 \mu \mathrm{g}$, Azithromycin. (AZM) $15 \mu \mathrm{g}$ and Gentamicin (CN) $120 \mu \mathrm{g}$. S. aureus and S. epidermis strains were tested for sensitivity to antimicrobials, including Gentamicin (CN) 120 $\mu \mathrm{g}$, Penicillin G (P) $10 \mu \mathrm{g}$, Oflaxacin (OFX) 5 $\mu \mathrm{g}$, and Chloramphenicol (C) $10 \mu \mathrm{g}$. For both the control and exposed to $2.4 \mathrm{GHz}$, standard inocula of 0.5 McFarland was swabbed on Müller Hinton agar then incubated 24 hours at $37^{\circ} \mathrm{C}$. The mean diameter of inhibition zones was recorded in $\mathrm{mm}$.

\section{Bacterial motility}

Among the studied pathogenic strains, Escherichia coli $0157 \mathrm{H} 7$ was the only motile bacterium. Therefore, a single colony of E. coli 
$0157 \mathrm{H} 7$ was inoculated in $5 \mathrm{ml}$ of Luria-Bertani (LB) broth (Sigma-Aldrich) and incubated at $37^{\circ} \mathrm{C}$ overnight with agitation at $200 \mathrm{rpm}$. Bacterial overnight culture $(1 \mu \mathrm{l})$ was injected into three spots on freshly prepared motility agar plates containing $0.5 \%$ agar (Motility Test Medium Himedia) [14]. The plates were incubated at $37^{\circ} \mathrm{C}$ for 24 and 48 hours under exposure of $2.4 \mathrm{GHz}$. The diameters of the bacterial growth rings were measured.

MTT and crystal violet assays

One colony forming unit (CFU) of each strain was transferred into $5 \mathrm{~mL}$ of Tryptic Soy Broth (TSB Oxoid) and incubated for 24 hours at $37^{\circ} \mathrm{C}$ with shaking. The cultures were diluted to $1 / 100$ in TSB to obtain 0.1 optical density (OD), at $595 \mathrm{~nm}$ for all bacterial inocula. Two hundred microliters of each bacterial inocula were transferred into 96 well plates in duplicate (control and exposed to $2.4 \mathrm{GHz}$ ) and incubated for 24 hours at $37{ }^{\circ} \mathrm{C}$; Biofilms were washed three times and subjected to 3-(4, 5-dimethylthiazol-2yl)-2, 5-diphenyltetrazolium bromide (MTT) assay to evaluate the viability of the biofilms and crystal violet based on the quantification of biofilm biomass.

The MTT reduction assay, which determines the metabolic activities of bacteria, was done as previously described with minor modifications $[15,16]$. Upon washing step, $10 \mu 1$ of 5 $\mathrm{mg} / \mathrm{ml}$ MTT (Sigma-Aldrich) was added to $100 \mu \mathrm{l}$ phosphate buffered saline (PBS) into each well, and the plates were incubated for 1 hour at $37^{\circ} \mathrm{C}$. A $100 \mu \mathrm{l}$ of solubilizing isopropanol was added to each well, and the plates were vigorously shaken. The amount of MTT formazan formed was measured by the ELx800 Universal Microplate Reader at a wavelength of $570 \mathrm{~nm}$. The pure TSB was used as blank. The results are shown as an index of cell metabolic activity and calculated by the formula: Index of cell metabolic activity $=(\mathrm{OD}$ sample - OD background $) /(\mathrm{OD}$ control - OD background) [17].

The quantitative assessment of biofilm for- mation was determined as previously described with minor modification $[18,19]$. Biofilms were stained with $200 \mu \mathrm{L}$ of $0.1 \%$ crystal violet. Excess stain was removed, and the wells were air-dried for 15 minutes and then the dye bounded to the adherent cells was solubilized with $200 \mu \mathrm{L}$ of $33 \%$ acetic acid. The OD of each solubilized liquid was measured at wavelength of $595 \mathrm{~nm}$. The pure TSB was used as blank. The results were shown as an index of biofilm formation and calculated by the same formula described above.

\section{Statistical analysis}

The data of this study are presented as means \pm standard errors of the means calculated from three repetitions of each experiment. The statistical analysis was conducted using Graphpad Prism 8 by mean of paired $t$ test. $P$ values $<0.05$ was statistically significant.

\section{Results}

Effect of $2.4 \mathrm{GHz}$ Wi-Fi exposure on antibiotic susceptibility

The susceptibility of Escherichia coli 0157H7, Staphylococcus aureus and Staphylococcus epidermis to various antibiotics was evaluated in the presence of Wi-Fi radiofrequency radiation. The data obtained for exposed and non-exposed (control) bacteria are represented in Tables 1 and 2.

The continuous exposure to Wi-Fi radiofrequency radiation decreased significantly the inhibition zone diameters of E. coli $0157 \mathrm{H} 7$ ( $p$ value $<0.05$ ) (Table 1). However, it revealed no significant changes in diameters of inhibition zones of $S$. aureus and S. epidermis (Table 2).

Effect of $2.4 \mathrm{GHz}$ Wi-Fi exposure on motility of E. coli 0157H7

The effect of Wi-Fi radiofrequency radiation on the motility of E. coli $0157 \mathrm{H} 7$ was evaluated by measuring the diameter of bacterial growth rings on motility agar medium after 
Table 1: Inhibition zone diameters ( $\mathrm{mm}$ ) for control and exposed Escherichia coli $0157 \mathrm{H} 7$ to $2.4 \mathrm{GHz}$ Wi-Fi radiofrequency radiation.

\begin{tabular}{lccc} 
Antibiotic & Control & $\begin{array}{c}\text { Wi-Fi } \\
\text { Exposure }\end{array}$ & P-value \\
\hline IPM 10 & $35.33 \pm 0.58$ & $29.67 \pm 0.58$ & $0.0002^{*}$ \\
\hline OFX 5 & $25.33 \pm 0.58$ & $21.67 \pm 0.58$ & $0.0014^{*}$ \\
\hline C 10 & $18.33 \pm 0.58$ & $12.33 \pm 0.58$ & $0.0002^{*}$ \\
\hline AZM 15 & $14.33 \pm 0.58$ & $11.33 \pm 0.58$ & $0.0031^{*}$ \\
\hline RD 30 & $16.67 \pm 0.58$ & $14.67 \pm 0.58$ & $0.0132^{*}$ \\
\hline MEM 10 & $29.33 \pm 0.58$ & $23.67 \pm 0.58$ & $0.0002^{*}$ \\
\hline LEV 5 & $31.67 \pm 0.58$ & $28.33 \pm 0.58$ & $0.0021^{*}$ \\
\hline CN120 & $30.33 \pm 0.58$ & $28.33 \pm 0.58$ & $0.0132^{*}$
\end{tabular}

Each value is the mean $\pm S D$ of three repetitions. ${ }^{*}$ statistically significant $(p<0.05)$

24 and 48 hours of Wi-Fi exposure. The data show significantly increased motility by $28 \%$ and $29 \%$ for 24 and 48 hours of 2.4 GHZ WiFi exposure, respectively, as compared to unexposed E. coli $0157 \mathrm{H} 7$ (Figure 1).

Effect of $2.4 \mathrm{GHz}$ Wi-Fi exposure on cell metabolic activity and biofilm formation

In order to explore the effects of Wi-Fi radiofrequency on the bacterial metabolic activity and biofilm formation, the MTT assay and crystal violet quantification were performed. The MTT test is based on the reduction of the yellow MTT dye by dehydrogenase in living cells to purple MTT formazan, which can be solubilized and quantified by spectrophotometric measurements. The crystal violet assay is based on the values of optical density of the crystal violet stain bonded to biofilm. Data obtained from bacterial metabolic activity and biofilm formation index are summarized in Table 3. As consequence of 24 hours exposure to $2.4 \mathrm{GHz} \mathrm{Wi}-\mathrm{Fi}$ radiofrequency radiation, results showed statistically significant 3 fold increase in cell metabolic activity and 1.9 fold raise in biofilm formation by exposed $E$. coli, S. aureus and S. epidermis as compared to controls (Table 3 ).

\section{Discussion}

The results of this study showed that 2.4 $\mathrm{GHz}$ Wi-Fi radiofrequency radiation induced a rise in the antibiotic resistance of $E$. coli $0157 \mathrm{H} 7$ but revealed no significant changes in that of $S$. aureus and S. epidermis. This observation coincides with the previous reports shown that exposure to electromagnetic fields (EMF) makes some bacteria resistant to antibiotics [8] and the effects of EMF exposure depend on the morphology of exposed cells [20]. Moreover, continuous 24 hours exposure to mobile $1.8 \mathrm{GHz}$ waves showed the presence of persisters Pseudomonas aeruginosa cells with enhanced antibiotic resistance [11]. In contrast, no significant effects of high frequency electromagnetic fields were revealed on anti-

Table 2: Inhibition zone diameters $(\mathrm{mm})$ for control and exposed S. aureus and S. epidermis to $2.4 \mathrm{GHz}$ Wi-Fi radiofrequency radiation.

\begin{tabular}{ccccccc}
\multirow{2}{*}{ Antibiotic } & \multicolumn{3}{c}{ S. aureus } & \multicolumn{3}{c}{ S. epidermis } \\
\cline { 2 - 7 } & Control & Wi-Fi Exposure & P-value & Control & Wi-Fi Exposure & p-value \\
\hline P 10 & $17.67 \pm 0.58$ & $16 \pm 1$ & 0.0667 & $13.67 \pm 0.58$ & $14.33 \pm 0.58$ & 0.2302 \\
\hline OFX 5 & $29.67 \pm 0.58$ & $28.67 \pm 0.58$ & 0.1011 & $28.33 \pm 0.58$ & $28.67 \pm 0.58$ & 0.5185 \\
\hline C 10 & $18.67 \pm 0.58$ & $17.33 \pm 0.58$ & 0.2302 & $15.33 \pm 0.58$ & $15.67 \pm 0.58$ & 0.5185 \\
\hline CN120 & $22.67 \pm 0.58$ & $22.33 \pm 0.58$ & 0.5185 & $23.33 \pm 0.58$ & $23.67 \pm 0.58$ & 0.5185
\end{tabular}




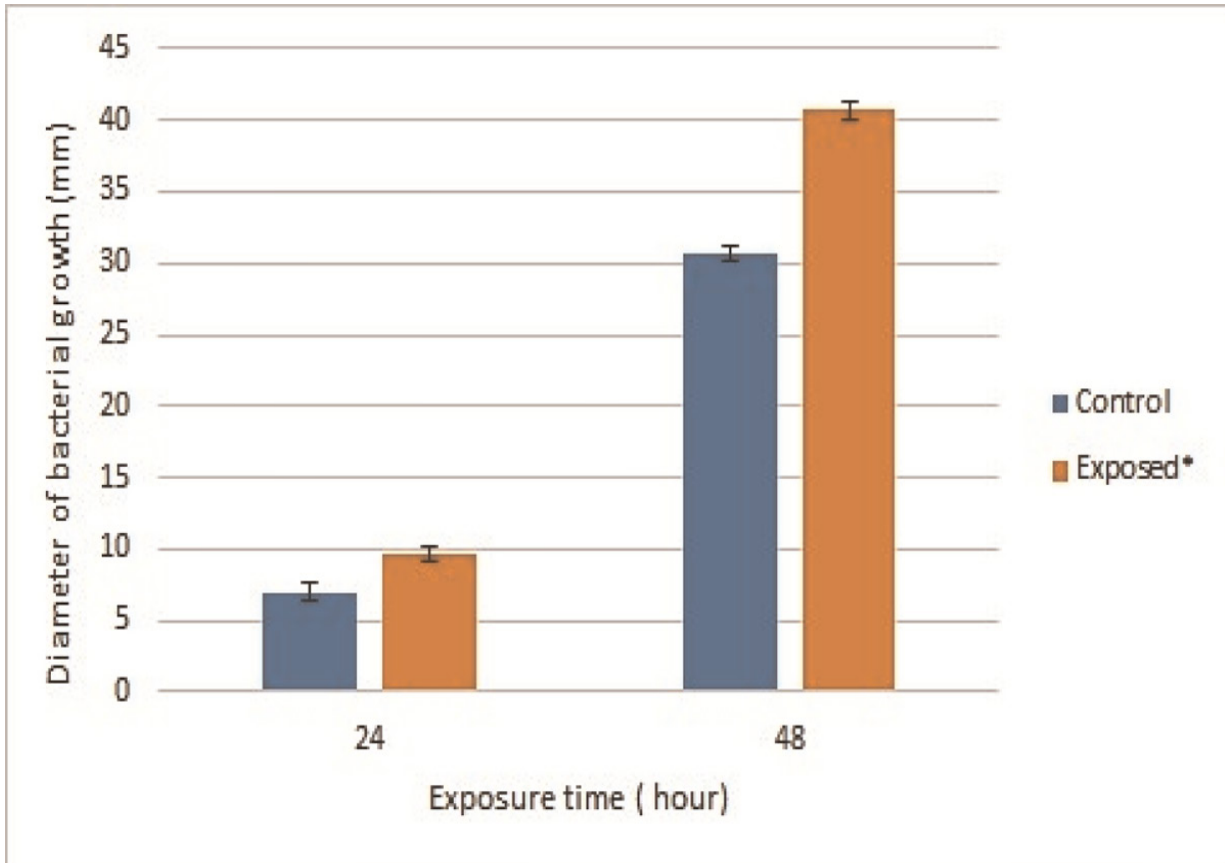

Figure 1: Motility of exposed E. coli $\mathrm{O} 157 \mathrm{H} 7$ to $2.4 \mathrm{GHz}$ Wi-Fi radiofrequency radiation. Each value is represented as mean $\pm \mathrm{SD}(\mathrm{n}=3)$. *Significance was considered at $(\mathrm{p}$-value $<0.05)$

Table 3: Effects of $2.4 \mathrm{GHz}$ Wi-Fi radiofrequency radiation on metabolic activity and biofilm formation of E. coli, S. aureus, and S. epidermis.

\begin{tabular}{ccccc} 
& & control & Exposed & P-value \\
\hline \multirow{2}{*}{ E. coli 0157H7 } & Cell metabolic activity & $1.018 \pm 0.023$ & $2.432 \pm 0.102$ & $0.002^{*}$ \\
\cline { 2 - 4 } & Biofilm formation & $1.009 \pm 0.080$ & $1.413 \pm 0.203$ & $0.042^{*}$ \\
\hline \multirow{2}{*}{ Staphylococcus aureus } & Cell metabolic activity & $1.026 \pm 0.081$ & $3.323 \pm 0.280$ & $0.004^{*}$ \\
\cline { 2 - 4 } Staphylococcus epidermis & Biofilm formation & $1.053 \pm 0.068$ & $1.918 \pm 0.223$ & $0.022^{*}$ \\
\cline { 2 - 4 } & Cell metabolic activity & $1.327 \pm 0.304$ & $3.024 \pm 0.267$ & $0.036^{*}$ \\
\cline { 2 - 4 } & Biofilm formation & $1.020 \pm 0.027$ & $1.506 \pm 0.062$ & $0.007^{*}$
\end{tabular}

Each value is the mean $\pm S D$. *statistically significant $(p<0.05)$

biotic sensitivity of exposed Staphylococcus [7]. The different effect seen in the present study between E. coli $0157 \mathrm{H} 7$ and $S$. aureus $\& S$. epidermis may be due to the difference in cell wall composition and how microwaves affect gram-positive and gram-negative bacteria. Several studies reported that radiation induced changes in membrane fatty acids and murein composition of bacteria as well as influenced antibiotic sensitivity [9,21]. Different antibiotics that act through various mechanisms were used in the current study, including inhibition of protein, DNA and cell wall synthesis. The radiation may alter the sensitivity of the efflux pumps or ion channels by permitting the entrance of the molecules through the bacterial cell wall $[8,22]$.

In addition to antibiotic resistance, there 
was a significant increase in $E$. coli $0157 \mathrm{H} 7$ motility after $2.4 \mathrm{GHz} \mathrm{Wi}-\mathrm{Fi}$ exposure, which may be a strategy of the pathogen's survival in the face of radiation stress. These results are in agreement with prior studies that showed promoting $E$. coli $0157 \mathrm{H} 7$ motility under heat and acid stress [23,24]. Flagella are critical virulence factors, that permit bacterial motility and promote adherence to mucins, the major component of the mucus that lines the gastrointestinal tract [25].

The current study examined the effects of exposing E. coli $0157 \mathrm{H} 7$, S. aureus and S. epidermis to Wi-Fi radiofrequency radiation 2.4 $\mathrm{GHz}$ on their cell metabolic activity and ability to form biofilms where bacterial cells treated with Wi-Fi radiation continuously for 24 hours. Previous reports studied the effects of extremely low frequency EMF exposure and short time Wi-Fi radiofrequency exposure on biofilm formation $[10,17]$. Based on the current study, the exposure of bacteria to $2.4 \mathrm{GHz}$ Wi-Fi radiofrequency radiation for 24 hours showed the statistically significant increase in the cell metabolic activity and ability to form biofilm of exposed E. coli, $S$. aureus and $S$. epidermis as compared to controls. Such finding agreed with previous observations for the influences of rotating magnetic field (RMF) on bacteria [17]. In contrast, short time exposure of Staphylococcus aureus to mobile phone electromagnetic waves did not affect their ability to form biofilm [10].

\section{Conclusion}

Based on our results, it can be concluded that Wi-Fi radiofrequency radiation affects bacterial strains in the stressful manner. Increasing antibiotic resistance, motility and biofilm formation which are pathogenic traits of bacteria is a worldwide threat to public health. There are some ambiguities that need further investigations regarding answering questions such as which cellular mechanism is responsible for this stress induced by EMF. Moreover, gene expression experiments are performed to clarify many uncertainties.

\section{Acknowledgment}

This work has been supported by grants from the Lebanese University.

\section{Conflict of Interest}

None

\section{References}

1. $\mathrm{Ng} \mathrm{K-H.} \mathrm{Non-ionizing} \mathrm{radiations-sources,}$ biological effects, emissions and exposures. Proceedings of the international conference on non-ionizing radiation at UNITEN. 2003:116.

2. Belyaev I. Non-thermal biological effects of microwaves. Microwave Review. 2005;11:1329.

3. Ishak NH, Ariffin R, Ali A, Sagiruddin MA, Tawi FMT, editors. Biological effects of WiFi electromagnetic radiation. 25-27 Nov. 2011. Penang: IEEE International Conference on Control System, Computing and Engineering; 2011.

4. Salmen SH. Non-Thermal Biological Effects of Electromagnetic Field on Bacteria-A Review. Am J Res Commun. 2016;4:16-28.

5. Cranfield C, Wieser HG, AI Madan J, Dobson J. Preliminary evaluation of nanoscale biogenic magnetite-based ferromagnetic transduction mechanisms for mobile phone bioeffects. IEEE Trans Nanobioscience. 2003;2:40-3. doi: 10.1109/tnb.2003.810155. PubMed PMID: 15382422.

6. Chang S, Choi J, Gil H, Yang J, Lee E, Jeon Y, et al. Genotoxicity evaluation of electromagnetic fields generated by $835-\mathrm{MHz}$ mobile phone frequency band. Eur J Cancer Prev. 2005:14:175-9. doi: 10.1097/00008469200504000-00014.

7. Salmen SH, Alharbi SA, Faden AA, Wainwright M. Evaluation of effect of high frequency electromagnetic field on growth and antibiotic sensitivity of bacteria. Saudi J Biol Sci. 2018;25:105-10. doi: 10.1016/j. sjbs.2017.07.006. PubMed PMID: 29379365; PubMed Central PMCID: PMC5775109.

8. Taheri M, Mortazavi SM, Moradi M, Mansouri S, Hatam GR, Nouri F. Evaluation of the Effect of Radiofrequency Radiation Emit- 
ted From Wi-Fi Router and Mobile Phone Simulator on the Antibacterial Susceptibility of Pathogenic Bacteria Listeria monocytogenes and Escherichia coli. Dose Response. 2017:15:1559325816688527. doi: 10.1177/1559325816688527. PubMed PMID: 28203122; PubMed Central PMCID: PMC5298474.

9. Taheri M, Mortazavi S, Moradi M, Mansouri S, Nouri F, Mortazavi S, et al. Klebsiella pneumonia, a microorganism that approves the non-linear responses to antibiotics and window theory after exposure to Wi-Fi $2.4 \mathrm{GHz}$ electromagnetic radiofrequency radiation. $J$ Biomed Phys Eng. 2015;5:115.

10.Mohd-Zain Z, Mohd-Ismail M, Buniyamin $N$. Effects of mobile phone generated high frequency electromagnetic field on the viability and biofilm formation of Staphylococcus aureus. World Acad Sci Eng Technol. 2012;70:221-4.

11.Nakouti I, Hobbs G, Teethaisong Y, Phipps D. A demonstration of athermal effects of continuous microwave irradiation on the growth and antibiotic sensitivity of Pseudomonas aeruginosa PA01. Biotechnol Prog. 2017;33:3744. doi: 10.1002/btpr.2392. PubMed PMID: 27792273.

12. March SB, Ratnam S. Sorbitol-MacConkey medium for detection of Escherichia coli 0157:H7 associated with hemorrhagic colitis. J Clin Microbiol. 1986;23:869-72. PubMed PMID: 3519658; PubMed Central PMCID: PMC268739.

13.Cockerill FR, Wikler MA, Alder J, Dudley M, Eliopoulos G, Ferraro M, et al. Performance standards for antimicrobial susceptibility testing: twenty-second informational supplement. Clinical and Laboratory Standards Institute. 2012;32:M100-S22.

14.Elmer W, Stephen D, William M, Paul C, Washington C. Color atlas and textbook of diagnostic microbiology. Philadelphia: Lippincott; 1992.

15.Wang $H$, Cheng $H$, Wang $F$, Wei $D$, Wang $X$. An improved 3-(4, 5-dimethylthiazol-2-yl)-2, 5-diphenyl tetrazolium bromide (MTT) reduction assay for evaluating the viability of Escherichia coli cells. J Microbiol Methods. 2010;82:330-3. doi: 10.1016/j.mimet.2010.06.014.
16.Saising J, Dube L, Ziebandt AK, Voravuthikunchai SP, Nega M, Gotz F. Activity of gallidermin on Staphylococcus aureus and Staphylococcus epidermidis biofilms. Antimicrob Agents Chemother. 2012;56:5804-10. doi: 10.1128/ AAC.01296-12. PubMed PMID: 22926575; PubMed Central PMCID: PMC3486563.

17.Fijalkowski K, Nawrotek P, Struk M, Kordas $M$, Rakoczy R. The effects of rotating magnetic field on growth rate, cell metabolic activity and biofilm formation by Staphylococcus aureus and Escherichia coli. Journal of Magnetics. 2013;18:289-96. doi: 10.4283/ jmag.2013.18.3.289.

18.Peeters E, Nelis HJ, Coenye T. Comparison of multiple methods for quantification of microbial biofilms grown in microtiter plates. J Microbiol Methods. 2008;72:157-65. doi: 10.1016/j.mimet.2007.11.010. PubMed PMID: 18155789.

19.Kwasny SM, Opperman TJ. Static biofilm cultures of Gram-positive pathogens grown in a microtiter format used for anti-biofilm drug discovery. Curr Protoc Pharmacol. 2010;50: 13A.8.1-23. doi: 10.1002/0471141755. ph13a08s50. PubMed PMID: 22294365. PubMed Central PMCID: PMC3272335.

20.Strašák L, Vetterl V, Fojt L. Effects of $50 \mathrm{~Hz}$ magnetic fields on the viability of different bacterial strains. Electromagn Biol Med. 2005;24:293300. doi: $10.1080 / 15368370500379715$.

21.Ayari S, Dussault D, Millette M, Hamdi M, Lacroix M. Changes in membrane fatty acids and murein composition of Bacillus cereus and Salmonella Typhi induced by gamma irradiation treatment. Int $J$ Food Microbiol. 2009;135:1-6. doi: 10.1016/j.ijfoodmicro.2009.07.012. PubMed PMID: 19651456.

22. Segatore B, Setacci D, Bennato F, Cardigno R, Amicosante G, Iorio R. Evaluations of the Effects of Extremely Low-Frequency Electromagnetic Fields on Growth and Antibiotic Susceptibility of Escherichia coli and Pseudomonas aeruginosa. Int J Microbiol. 2012;2012:587293. doi: $\quad 10.1155 / 2012 / 587293$. PubMed PMID: 22577384; PubMed Central PMCID: PMC3335185.

23.Chung H, Bang W, Drake M. Stress response of Escherichia coli. Compr Rev Food Sci. Food Saf. 2006;5:52-64.

24. House B, Kus JV, Prayitno N, Mair R, Que 
L, Chingcuanco F, et al. Acid-stress-induced changes in enterohaemorrhagic Escherichia coli 0157: H7 virulence. Microbiology. 2009;155:2907-18. doi: 10.1099/ mic.0.025171-0. PubMed PMID: 19497950.

25.Erdem AL, Avelino F, Xicohtencatl-Cortes J,
Giron JA. Host protein binding and adhesive properties of $\mathrm{H} 6$ and $\mathrm{H} 7$ flagella of attaching and effacing Escherichia coli. J Bacteriol. 2007;189:7426-35. doi: 10.1128/JB.0046407. PubMed PMID: 17693516; PubMed Central PMCID: PMC2168434. 